\title{
EDILBERTO M. JOSE, MD (1946 - 2019) Otorhinolaryngologist, Head \& Neck Surgeon, Mentor, Friend
} Ruzanne Magiba-Caro, MD

Dr. Ed Jose is (and will always be) my best friend --- my mentor, guidance counselor and the "kuya" that I never had. I would like to share with you his two constant reminders to me which will make us know, understand and appreciate him more.

Very few people can handle power.

He was a prime example of "not seeking any position but rather the position seeking him." He was Chairman of the Department of Otorhinolaryngology, University of the Philippines - Philippine General Hospital (UPPGH) and at the same time President of the Philippine Society of OtorhinolaryngologyHead and Neck Surgery. He also became Chairman of the Philippine Board of Otorhinolaryngology-Head and Neck Surgery.

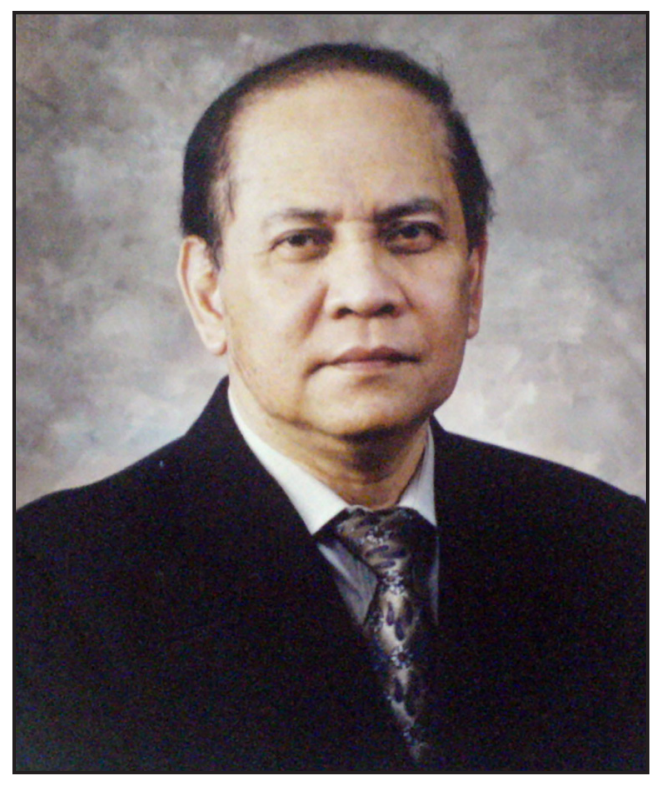

especially during difficult and complicated surgeries. Papa Ed's presence in the OR was a "confidence booster" for all of us. A true head and neck surgeon who did sharp dissection with bravado, the "thyroid and parotid expert," the "surgeon's surgeon" - Daddy Joe was very decisive and pragmatic in the management of cases. He had numerous patients and surgeries, always ready with an alternate case, and was also known as the "extension king" of UP-PGH. He was a silent worker but a very witty colleague. He was abreast of all the developments in the field of ORL. In fact, it was during his term as PSO-HNS President that the First PSO-HNS Clinical Practice Guidelines were developed and disseminated. Proof of his dedication to ORL training was his serving as At one point, he was also Assistant Director for Health Operations of UP-PGH. Committed to his positions, Dr. Jose remained humble and unassuming. He may appear "suplado" but he was always willing to help in whatever way possible. He was quite flexible believing that "rules can be bent" if it was the right thing to do at the time. One of his favorite songs was "Both Sides Now" and indeed, he was always fair when very important decisions were made.

Simplify...Simplify...Simplify...

This explains why his dedication was unwavering. Dr. Ed focused on three important aspects of his life: family, clinical practice and ORL training.

Married to a pathologist (Dr. Rebecca Tongco-Jose) who passed away three years ago, his primary concern up to the end were his sons Noel and lan. His world revolved around his family.

The University of the Philippines (UP) was his way of life where he obtained his secondary, college and medical education. He took his residency at UP-PGH and served as chief resident on his senior year. Upon his return from Fellowship in Head and Neck Surgery at the Royal Nose, Throat and Ear Hospital in England, he started teaching and training residents at UP-PGH ... and never stopped even after retirement. Fortunately for all the residents and even young consultants in UP-PGH, his clinic was just across Taft Avenue - so he was forever ON CALL director of the PBO-HNS until his demise. He made it a point to attend all the meetings, workshops, accreditation visits and other related activities (actually missing out on some social obligations). He was also ON CALL when other directors were not available.

Dr. Jose was very religious, a practicing Roman Catholic and a devotee of Our Lady of Manaoag. He never failed to pray before seeing a patient and commencing surgery.

He may seem grumpy but having known him for 35 years, he can be very playful with a very good sense of humor. Recognized as the FPJ of ORL, he would occasionally boast of his female admirers. He declared to our family that our grandson was his "adopted apo" and he had a "pasalubong only for Teo" every time he went on an accreditation visit. He was a voracious reader and a lover of history. Dr. Ed Jose was a simple man. His only luxury was collecting cars and watches.

The last time I saw DJ (that is how our family calls him) prior to his hospitalization was significant because my mentor came to my clinic in Quezon City to consult me regarding his ear problem. True to form, I ended up consulting him for my nasal complaint.

It will not only be I who will miss Dr. Ed Jose and his signature laughter...the entire ORL community will miss their Papa Ed/Daddy Joe. He will forever remain as an inspiration and role model for any Otorhinolaryngologist - Head and Neck Surgeon. 